\title{
High-Specific Isolation and Instant Observation of Circulating Tumour Cell from HCC Patients via Glypican-3 Immunomagnetic Fluorescent Nanodevice
}

\author{
Qihui Chu',* \\ Weiwei Mu (D) ${ }^{1}, *$ \\ Chuanjin Lan ${ }^{2}$ \\ Yang Liu' \\ Tong Gao' \\ Li Guan' \\ Yuxiao Fang' \\ Zipeng Zhang' \\ Yingchao Liu $^{2}$ \\ Yongjun Liu' \\ Na Zhang'
}

'Department of Pharmaceutics, Key Laboratory of Chemical Biology (Ministry of Education), School of Pharmaceutical Sciences, Cheeloo College of Medicine, Shandong University, Jinan, 250012 . People's Republic of China; ${ }^{2}$ Department of Neurosurgery, Shandong Provincial Hospital Affiliated with Shandong First Medical University, Jinan, 25002I.

People's Republic of China

*These authors contributed equally to this work

\begin{abstract}
Purpose: Specific targeting receptors for efficiently capturing and applicable nanodevice for separating and instant observing of circulating tumour cells (CTC) are critical for early diagnosis of cancer. However, the existing CTC detection system based on epithelial cell adhesion molecule (EpCAM) was seriously limited by low expression and poor specificity of targeting receptors, and not instant observation in clinical application.
\end{abstract}

Methods: Herein, an alternative glypican-3 (GPC3)-based immunomagnetic fluorescent system (C6/MMSN-GPC3) for high-specific isolation and instant observation of CTC from hepatocellular carcinoma (HCC) patients' peripheral blood was developed. The high-specific HCC targeting receptor, GPC3, was employed for improving the sensitivity and accuracy in CTC detection. GPC3 monoclonal antibody (mAb) was linked to immunomagnetic mesoporous silica for specific targeting capture and separate CTC, and fluorescent molecule coumarin-6 (C6) was loaded for instant detection of CTC.

Results: The cell recovery (\%) of C6/MMSN-GPC3 increased in 106 HL-60 cells (from $49.7 \%$ to $83.0 \%$ ) and in whole blood (from $42 \%$ to $80.3 \%$ ) compared with MACS ${ }^{\circledR}$ Beads. In clinical samples, the C6/MMSN-GPC3 could capture more CTC in the 13 cases of HCC patients and the capture efficiency was improved by $83.3 \%-350 \%$. Meanwhile, the capture process of C6/MMSN-GPC3 was harmless, facilitating for the subsequent culture. Significantly, the C6/MMSN-GPC3 achieved the high-specific isolation and instant observation of CTC from HCC patients' blood samples, and successfully separated CTC from one patient with early stage of HCC (Stage I) and one post-surgery patient, further indicating the potential ability of C6/MMSN-GPC3 for HCC early diagnosis and prognosis evaluation. Conclusion: Our study provides a feasible glypican-3 (GPC3)-based immunomagnetic fluorescent system (C6/MMSN-GPC3) for high-specific isolation and instant observation of HCC CTC.

Keywords: immunomagnetic fluorescent system, circulating tumour cells, hepatocellular carcinoma, glypican-3, early diagnosis

\section{Introduction}

The incidence rate of liver cancer is increasing most rapidly, according to cancer statistics 2020 , with $2 \%$ to $3 \%$ annually from 2007 to $2016 .{ }^{1}$ Hepatocellular carcinoma (HCC) is the dominant form of liver cancer, with a low five-year survival rate. About $80 \%$ of HCC patients were diagnosed at an advanced stage of the disease with rapid progression, high cost, and poor effect due to the lack of
Correspondence: Yongjun Liu; Na Zhang Email liuyongjun@sdu.edu.cn; zhangnancy9@sdu.edu.cn 
symptoms during the early stages of $\mathrm{HCC}^{2}$ Increasing the accuracy of early diagnosis is the best way to improve the prognosis of HCC. At present, the diagnostic methods of cancer mainly include imaging techniques, tissue biopsies, and liquid biopsies. ${ }^{3}$ Liquid biopsies, including the detection of circulating tumour cells (CTC), circulating tumour DNA (ctDNA) and exosomes, etc., are emerging reliable diagnostic method with the advantages of non-invasive, repeatable, and the ability of early diagnosis. ${ }^{4,5}$ There were some biomarkers for HCC in clinical practice, such as alpha-fetoprotein (AFP), AFP lectin fraction (AFP-L3), and des- $\gamma$-carboxy prothrombin (DCP), and the markers above often revealed false-positive outcomes, due to lack of sufficient sensitivity and specificity. ${ }^{6}$ In the last couple of years, increasing attention has been paid to CTC, and the existence of CTC in cancer patients' peripheral blood has displayed potential clinical value as a novel biomarker. ${ }^{7,8} \mathrm{CTC}$, which is shed from the primary tumour into the blood circulatory system, entered the circulatory system long before a tumour is diagnosed. ${ }^{9}$ Clinical research findings have exhibited that CTC can be discovered in the blood, while the size range of tumours is only 1-2 $\mathrm{mm}$, which is far earlier than conventional detection methods, such as images logical diagnosis. ${ }^{10,11}$ Thus, selective capture of CTC from the blood sample is very powerful evidence for the early diagnosis of cancer.

The main challenge for CTC isolation is to achieve high-specific capture and separation of extremely rare CTC from billions of background cells. ${ }^{12,13}$ Specific targeting receptor is a critical matter to efficiently recognize and capture of CTC for HCC early diagnosis. Epithelial cell adhesion molecule (EpCAM)-targeting immunomagnetic beads, CellSearch ${ }^{\circledR}$, was the unique clinical CTC detection system approved by the Food and Drug Administration (FDA) for cancer diagnostics, including breast, prostate and colorectal cancer. ${ }^{14}$ However, for the detection of the CTC of HCC, the EpCAM-based immunomagnetic beads showed low sensitivity because there are less than $30 \%$ clinical cases of HCC expressing EpCAM. ${ }^{13}$ Therefore, developing more sensitive detection methods for HCC is an urgent need. For example, Zhang et al designed the system modified with the asialoglycoprotein receptor (ASGPR) antibody to capture the HCC cells. ${ }^{15}$ Xie et al conjugated EpCAM and Sialyl Lewis $\mathrm{X}$ (Slex) antibody on dendrimers to capture CTC in hepatocellular carcinoma patients' blood samples. ${ }^{16}$ The researches made good progress, and there still existed the problem that ASGPR and Slex were not widely expressed in HCC CTC. As a result, new targeting receptors with high, stable and specific expression in HCC for CTC capturing are urgently pursued. Glypican-3 (GPC3), as a superior marker of HCC, has a specific distribution in HCC tumour cells and with the overexpression even at the incipient stages of the HCC. ${ }^{17}$ GPC3 is highly expressed in $\mathrm{HCC}$ cases but not expressed in normal adult organs. ${ }^{18}$ Our previous study showed GPC3 as a specific-targeting receptor could contribute to early diagnosis of HCC and achieve combination efficiency of theranostics. ${ }^{19}$ As a consequence, it is assumed that a GPC3-targeting strategy would possess potential clinical application for CTCbased early diagnosis of HCC.

Nanodevices have a significant effect on capturing CTC efficiently. Currently, diverse platforms have been developed to selectively isolate CTC, including immunomagnetic beads, microfluidic, and those methods relied on physical properties. ${ }^{20}$ Within them, the immunomagnetic beads are the only clinical approach. Immunomagnetic beads apply magnetic beads as the core for isolation, and antibodies conjugate on the surface of magnetic beads for a specific combination of CTC. ${ }^{21}$ CTC are separated by employing an external magnetic field. Immunomagnetic beads showed promising prospects for CTC detection due to its easy manipulation, high surface-volume ratio, excellent magnetic enrichment function, and good biocompatibility. $^{22}$ Thus, different nanodevice based immunomagnetics have been developed for capturing CTC, including liposomes, ${ }^{23}$ dendrimers, ${ }^{24}$ graphene oxide nanocarriers, ${ }^{25}$ cell membrane bionic nanocarriers, ${ }^{26}$ and mesoporous silica nanocarriers. Among them, mesoporous silica nanocarriers have superior properties, including the extensive surface area, large pore volume, ease of functionalization, controllable pore structure, and high thermal and mechanical stability. ${ }^{27}$ Magnetic mesoporous silica nanoparticles are developed as multifunctional magnetic-fluorescent nanoplatforms with the sufficient mesoporous volume for fluorescein carrying and facile surface functionalization for the targeting molecules cross-linking. Previous studies showed magnetic mesoporous silica nanoparticles had good application prospects for the isolation and detection of CTC. ${ }^{28}$ In our design, mesoporous silica coating could improve the stability of the magnetic beads and provide silanols groups to enhance the GPC3 antibody binding due to magnetic beads' lack of active groups. Meanwhile, the ordered mesoporous structure was capable of loading 
fluorescent molecules, such as coumarin-6 (C6), to monitor the CTC capture process and instantly observe CTC.

In this study, the HCC CTC capturing system based on CPC3 targeting immunomagnetic fluorescent nanodevice (C6/MMSN-GPC3) was constructed for the first time (Scheme 1). Subsequently, the capture efficacy of C6/MMSN-GPC3 compared to EpCAM magnetic beads (MACS ${ }^{\circledR}$ Beads) was studied. In mimic clinical samples, the cell recovery (\%) of C6/MMSN-GPC3 increased by $33.3 \%$ in $10^{6} \mathrm{HL}-60$ cells and $38.3 \%$ in $1 \mathrm{~mL}$ whole blood compared with MACS ${ }^{\circledR}$ Beads. In clinical samples, the C6/MMSN-GPC3 could capture more CTC and the capture efficiency was improved by $144.9 \%$ in the 13 cases of HCC patients. The capture process showed no invasiveness in the cell activity, migration and proliferation ability. In view of the high-specific isolation and instant observation, the nanodevice was utilized in 20 cases of HCC patients' peripheral blood and achieved accurate detection of CTC. On consideration of the above, C6/MMSNGPC3 displayed the potential clinical application for
HCC early diagnosis through the convenient CTC isolation and instant observation.

\section{Materials and Methods Materials}

$\mathrm{Fe}_{3} \mathrm{O}_{4}$ solution $(5 \mathrm{mg} / \mathrm{mL})$ was purchased from Xi'an ruixi Biological Technology Co., Ltd. Mal- $\mathrm{PEG}_{2000}-\mathrm{COOH}$ was obtained from AVT (Shanghai) Pharmaceutical Tech Co., Ltd. Anti-human Glypican-3 antibody was purchased from Abcepta Biotech Ltd. Co. APC anti-human CD45 antibody was purchased from Biolegend (DAKEWE, Shenzhen, China). PE anti-human CK18 were purchased from Biosynthesis Biotechnology Inc. (Beijing, China). CD326 (EpCAM) MicroBeads were purchased from Miltenyi. And other reagents and solvents were obtained from Sinopharm Co., Ltd (Shanghai, China) and SigmaAldrich Co., Ltd (Shanghai, China).

\section{Cell Culture}

Human HCC cells (HepG2 and Hepa1-6) were obtained from American Type Culture Collection (ATCC). Huh7

A

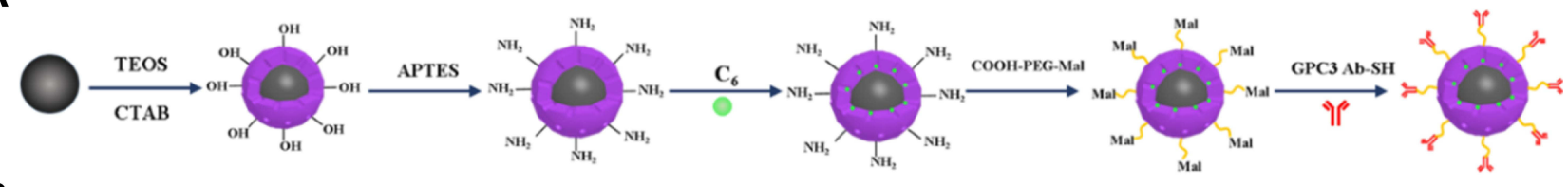

B
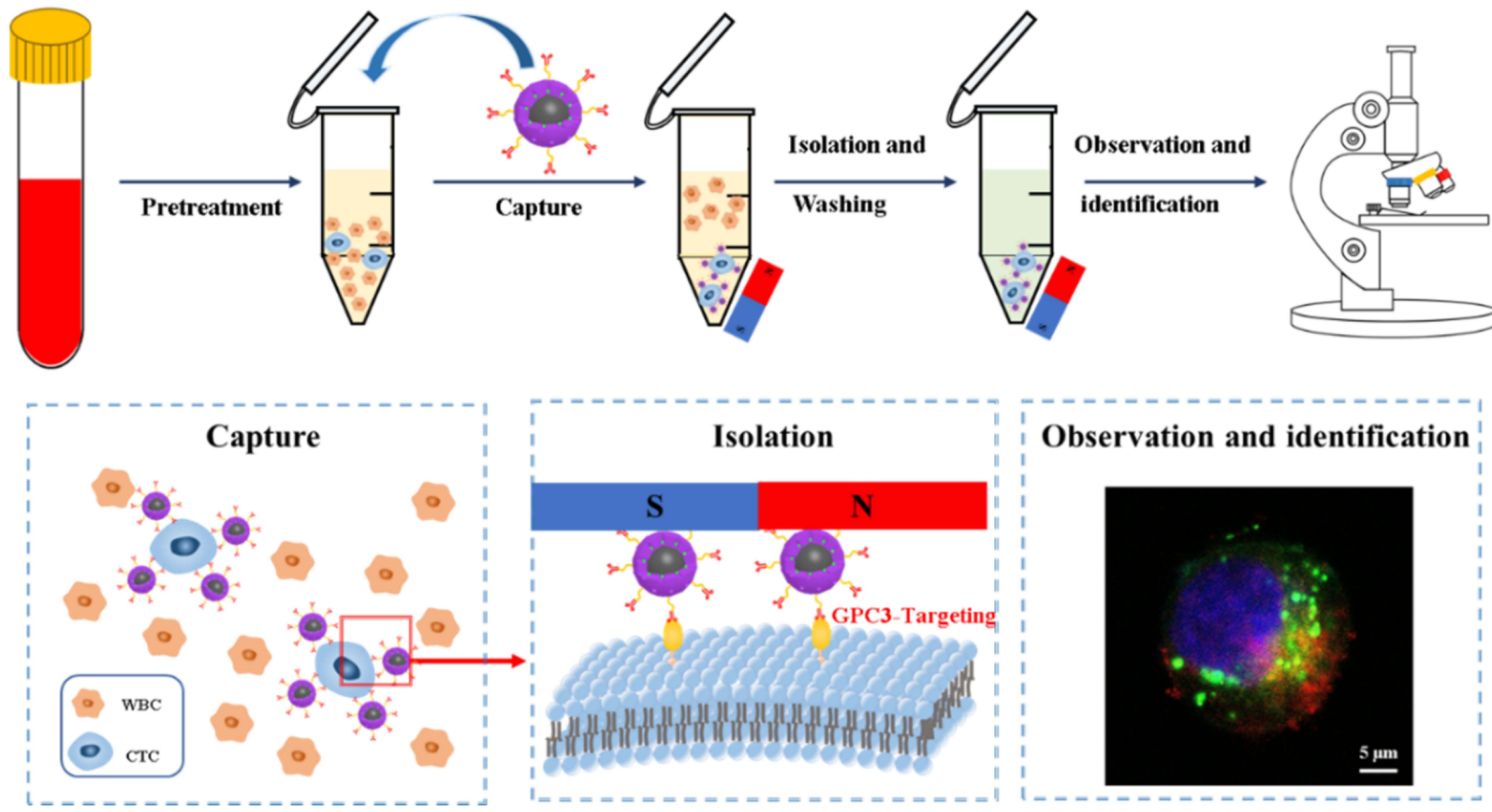

Scheme I Scheme of C6/MMSN-GPC3 achieves high-specific capture, isolation, and observation for HCC CTC via the GPC3-targeting immunomagnetic fluorescent nanodevice. (A) Preparation of the C6/MMSN-GPC3 and (B) the procedure of CTC capturing, isolation, and observation. 
cells, Jurkat T cells and HL-60 cells were purchased from Cell Bank of the Chinese Academy of Sciences (Shanghai, China). HepG2, Huh7 and Hepa1-6 cells were cultured in Dulbecco's modified Eagle's medium media. Jurkat T cells and HL-60 cells were cultured in RPMI-1640 media. Both the culture media were supplemented with $10 \%(\mathrm{v} / \mathrm{v})$ fetal bovine serum.

\section{Synthesis of MMSN}

The MMSN was prepared by modified sol-gel methods. First, $0.5 \mathrm{~g} \mathrm{CTAB}$ and $100 \mu \mathrm{L}$ trimethylamine were added into $20 \mathrm{~mL}$ deionized water. Then, the solution was stirred vigorously under the condition of $80^{\circ} \mathrm{C}$ for $1 \mathrm{~h} .1 .5 \mathrm{~mL}$ $\mathrm{Fe}_{3} \mathrm{O}_{4}$ nanoparticles solution $(5 \mathrm{mg} / \mathrm{mL})$, treated with ultrasonic previously for $1 \mathrm{~h}$, was added to $50 \mathrm{~mL}$ threenecked flask dropwise. Finally, $0.5 \mathrm{~mL}$ TEOS was added and the reaction lasted for another $2 \mathrm{~h}$ at $80^{\circ} \mathrm{C}$ to finish the sol-gel reaction. The precipitate, separated by an external magnetic field, was washed with deionized water and ethyl alcohol several times and dried overnight at room temperature under a vacuum. The products were refluxed for $6 \mathrm{~h}$ in $60 \mathrm{~mL}$ ethanol solution containing $\mathrm{NH}_{4} \mathrm{NO}_{3}(6 \mathrm{mg} /$ $\mathrm{mL}$ ) to remove the CTAB template.

\section{Synthesis of $\mathrm{MMSN}-\mathrm{NH}_{2}$}

$40 \mathrm{mg}$ of MMSN were ultrasonically dispersed in distilled water and heated to $80^{\circ} \mathrm{C}$. Then, $0.06 \mathrm{mmol}$ APTES was added to the MMSN suspension and reacted at $80^{\circ} \mathrm{C}$ for $1 \mathrm{~h}$ in the protection of $\mathrm{N}_{2}$ atmosphere. Finally, the synthesized MMSN-NH$H_{2}$ nanoparticles were collected via centrifugation, washing, and drying.

\section{Synthesis of $\mathrm{C} 6 / \mathrm{MMSN}-\mathrm{NH}_{2}$}

$4 \mathrm{mg}$ coumarin- 6 and $40 \mathrm{mg} \mathrm{MMSN}-\mathrm{NH}_{2}$ were dissolved in methyl alcohol with mechanical stirring in the dark at room temperature until the methyl alcohol was stirred to dry. Then, the solid product was dissolved in methyl alcohol and centrifuge quickly to remove the external C6 absorbed on the surfaces and obtain the $\mathrm{C} 6 / \mathrm{MMSN}-\mathrm{NH}_{2}$. The concentration of $\mathrm{C} 6$ in the initial solution and the supernatant solution were measured by an ultraviolet spectrophotometer.

\section{Synthesis of C6/MMSNs-PEG $2000-M a l$}

$0.02 \mathrm{mmol}$ Mal-PEG $\mathrm{PEo0}_{20 \mathrm{COH}}$ and $0.044 \mathrm{mmol}$ EDC were stirred in deionized water to activate the carboxyl groups. Then, $40 \mathrm{mg}$ MMSN-NH$H_{2}$ and $0.044 \mathrm{mmol}$ triethylamine were added to the above $\mathrm{Mal}-\mathrm{PEG}_{2000^{-}}$
$\mathrm{COOH}$ solution. The reaction was carried out for $24 \mathrm{~h}$ under the $\mathrm{N}_{2}$ protection. Finally, the suspension was centrifuged and the precipitate was washed, and dried to obtain C6/MMSN-PEG 2000 -Mal.

\section{Preparation of C6/MMSN-GPC3}

Briefly, GPC3 antibody was reacted with Traut's reagent for thiolation at the molar ratio of 1:20 in PBS buffer $(\mathrm{pH}$ 7.8 8.0, including $4 \mathrm{mM}$ EDTA) and under $\mathrm{N}_{2}$ atmosphere. The purification of thiolated GPC 3 antibody was conducted by means of a Zeba Desalt spin column (Thermo Scientific, US). Then, $40 \mathrm{mg}$ C6/MMSN-PEG 2000 -Mal was ultrasonically dispersed in PBS buffer (pH 7.8 8.0, containing $4 \mathrm{mM}$ EDTA) and added to the above solution. The reaction was carried out overnight. The free thiolated GPC 3 antibody was removed by centrifugation. The final obtained precipitation was C6/MMSN-GPC3.

\section{Characterizations of C6/MMSN-GPC3}

The morphology of C6/MMSN-GPC3 was evaluated with transmission electron microscopy (TEM). Zeta potential was measured by the Nano ZS90 (Malvern Instruments, UK). The superparamagnetic properties in fields ranging from 0 to 20,000 K were measured using a vibrating sample magnetometer (VSM, LakeShore7404, UN). Element analysis was performed using a high-resolution transmission electron microscope. The preparation process was characterized by Fourier transform infrared (FTIR) spectra (Nicolet, US). To prove the successful antibody modification, GPC3 antibody labeled with Rhodamine B ( $\mathrm{RhB})$ was reacted with $\mathrm{C} 6$ / MMSN-PEG ${ }_{2000}$ and then observed under confocal laser scanning microscopy (CLSM).

\section{Capture Condition Optimization of $\mathrm{C} 6 /$ MMSN-GPC3}

An ideal CTC enrichment system should possess superior conditions for capturing targeted tumor cells. To determine the optimal assay concentration and time of C6/MMSNGPC3, we first examined the capture efficiency by incubating HepG2 cells $\left(10^{5}\right.$ cellsmL $\left.^{-1}\right)$ with different concentrations (ranging from 50, 100, 200, 300, 400, 500, $600 \mu \mathrm{g} / \mathrm{mL}$ ) and different time (ranging from $5 \mathrm{~min}$ to $60 \mathrm{~min}$ ) of C6/MMSNGPC3, respectively. After magnetic isolation, the unrecognized cells in the supernatant fluid were collected and counted using a cell counter (JIMBIO) to calculate the capture efficiency. The capture efficiency (\%) was evaluated using the following formula: Capture Efficiency 
$(\%)=\left(\mathrm{C}_{0}-\mathrm{C}_{1}\right) / \mathrm{C}_{0} * 100 \%$, in which $\mathrm{C}_{0}$ is the total cells counts, and $\mathrm{C}_{1}$ is the unrecognized cells counts in the supernatant. Meanwhile, the collected cells nuclei were stained with Hoechst 33342 for $10 \mathrm{~min}$ and then washed with PBS three times to observe with a fluorescence microscope. To verify the binding specificity of C6/MMSN-GPC3, Jurkat T cells were served as the control group. The capture process was performed as stated above.

\section{Targeting Binding Ability Assay of C6/ MMSN-GPC3}

The targeting binding ability of C6/MMSN-GPC3 and C6/ MMSN-PEG 2000 to the adherent and suspensory HepG2 cells was investigated. For the adherent HepG2 cells, the cells were seeded at $1.0 \times 10^{5}$ cells per well into 12 -well plates and incubated overnight at $37^{\circ} \mathrm{C}$. C6/MMSN-GPC3 and C6/MMSN-PEG 2000 (final concentration: $400 \mu \mathrm{g} / \mathrm{mL}$ ) was added and incubated with the cells for $30 \mathrm{~min}$, respectively. Subsequently, the cells were stained with Hoechst 33342 and washed with cold PBS several times. Finally, the cells were imaged and observed under fluorescence microscope. To quantitatively evaluate the cellular uptake, the cells were trypsinized and resuspended in PBS, and then the fluorescence intensity was determined by flow cytometry. For the suspensory HepG2 cells, the cells were inoculated into 6-well plates and incubated with $400 \mu \mathrm{g} / \mathrm{mL}$ C6/MMSN-GPC3 and C6/MMSN-PEG 2000 for $30 \mathrm{~min}$, respectively. After magnetic separation, the analysis methods were performed to follow the same steps as above. Other cell lines (Hepa1-6 and Huh-7) overexpressed GPC3 were performed with the above methods to further validate the C6/MMSN-GPC3 with a specific targeting binding ability to the cells with high GPC3 expression.

\section{Capture Performance Comparison Between C6/MMSN-GPC3 and MACS ${ }^{\circledR}$ Beads in Mimicking Clinical Samples}

To comparatively evaluate the capture performance between C6/MMSN-GPC3 and commercially available MACS $^{\circledR}$ Beads, both platforms were applied to mimic clinical samples. In brief, 100 HepG2 cells were suspended in $1 \mathrm{~mL} 10^{6} \mathrm{HL}-60$ cells and $1 \mathrm{~mL}$ whole blood, and then treated with CD326 (EpCAM) MACS $^{\circledR}$ Beads and C6/MMSN-GPC3, respectively. After separating through an applied magnetic field, a three-color ICC method was performed to identify the captured cells and the captured cells were calculated via CLSM.

\section{Limit of Detection (LOD) Study of C6/ MMSN-GPC3}

As CTC number was the promising indicator of early screening, disease progression and survival during cancer metastasis, the sensitivity of C6/MMSN-GPC3 was determined. To study the sensitivity of the C6/MMSN-GPC3 towards HepG2 cells, artificial samples at a low CTC concentration close to clinical samples were prepared as follows: different numbers of HepG2 cells stained with Hoechst 33342 (10, 20, $50,100,150$ and 200, respectively) were spiked into $10^{6} \mathrm{HL}-$ 60 cells, followed by addition of C6/MMSN-GPC3. After 30 min of incubation, the enrichment process was followed by the above procedures. The collected cells were resuspended in PBS and calculated under a fluorescence microscopy.

\section{Migration and Proliferation Ability Investigation of the Captured HepG2 Cells}

CTC could provide information on HCC patient prognosis assessment, treatment monitoring, the progressionfree survival and overall survival prediction, consequently guided clinicians to develop personalized treatment strategies for HCC therapy so that migration and proliferation ability of HepG2 cells were primarily investigated after magnetic separation. Firstly, wound healing assay was carried out to study the migration ability, which procedure consisted of making a wound in a cell monolayer, taking the images during cell migration to close the wound at $0 \mathrm{~h}, 12 \mathrm{~h}, 24 \mathrm{~h}$, and comparing migration rate with the control group without any treatment. In addition, the captured cells were re-cultured on a 12-well plate for different time periods $\left(12 \mathrm{~h}, 24 \mathrm{~h}, 1^{\text {st }}\right.$ passage, $2^{\text {nd }}$ passage, and $3^{\text {rd }}$ passage) to investigate the proliferation activity. The carrier's biocompatibility and safety were evaluated by methylthiazol tetrazolium (MTT) assay. Briefly, HepG2 cells at a density of 5000 cells per well were grown on 96-well plates and cultured for $24 \mathrm{~h}$ to make cells adhesion. A series of concentration of $\mathrm{C6} /$ MMSN-GPC3 $(1,10,100,200,400 \mu \mathrm{g} / \mathrm{mL})$ were added to the cells culturing $24 \mathrm{~h}$. After adding MTT and DMSO, the absorbance was read at $570 \mathrm{~nm}$ using a microplate reader (BIO-Tek, USA). The relative cell viability (\%) was figured out by the following equation: Relative cell viability $(\%)=\left(\mathrm{A}_{\text {sample }} / \mathrm{A}_{\text {control }}\right) \times 100 \%$. 


\section{Capture Performance from HCC Patient Blood Samples of C6/MMSN-GPC3}

The experiment was approved by Ethics Committee of Shandong University. All participants signed informed consent. The clinical blood samples were collected from HCC patients and healthy volunteers. And the collected blood was stored in an anticoagulant tube and treated as soon as possible. The peripheral blood was pretreated with Ficoll-Paque solution to extract mononuclear cells (PBMCs) including CTC. After washing with PBS, the PBMCs including CTC were suspended in PBS and treated with C6/MMSN-GPC3 for $30 \mathrm{~min}$. After magnetic separation, the captured cells were fixed with 4\% Paraformaldehyde Fix Solution (PFA) for $30 \mathrm{~min}$, and permeabilized with $0.2 \%$ Triton X-100 for 10 min. After being washed by PBS, the cells were immersed in the block solution 5\% fetal calf serum for 30 min. Finally, the captured cells were stained with PE-CK18 and APC-CD45 at $4{ }^{\circ} \mathrm{C}$ for $4 \mathrm{~h}$ in the darkness, and then DAPI was added to stain the cell nucleus for $10 \mathrm{~min}$. Stained cells were resuspended in PBS and observed under the CLSM. CTC was characterized as CD45-/CK18+/DAPI +/C6+, while WBC was identified as CD45+/CK18-/DAPI +/C6-. The use of MACS ${ }^{\circledR}$ Beads was followed by the instructions. And the comparison between C6/MMSNGPC3 and MACS ${ }^{\circledR}$ Beads was evaluated with $2 \mathrm{~mL}$ blood samples from one HCC patients.

\section{Statistical Analysis}

Statistical significant differences were analyzed by Student's $t$-test, and $p<0.05$ were regarded as the existing statistical differences. All results were presented as the mean \pm standard deviation (SD).

\section{Results and Discussion Preparation and Characterization of $\mathrm{C6} /$ MMSN-GPC3}

The morphology of C6/MMSN-GPC3 was observed by transmission electron microscopy (TEM) (Figure 1A). The TEM images revealed that C6/MMSN-GPC3 had a core-shell structure with an iron oxide core and a silica shell. The size of C6/MMSN-GPC3 was around 113.1 \pm $7.7 \mathrm{~nm}$ (Figure 1B). C6/MMSN-GPC3 showed superparamagnetic properties and the saturation magnetization value was $11.73 \mathrm{emu}^{-1}$ at room temperature, which was sufficiently used for magnetic separation (Figure 1C). The synthetic process of C6/MMSN-GPC3 was also characterized by the FTIR technique (Figure 1D).
MMSN-NH ${ }_{2}$ exhibited a new absorption peak at $1552 \mathrm{~cm}^{-1}$ when compared with MMSN, which was attributed to the stretching vibration of $-\mathrm{NH}_{2}$ bending, proving the emergence of amino groups on the surface of MMSN. C6/MMSN- PEG $_{2000}$-Mal displayed new stretching vibration at $2856 \mathrm{~cm}^{-1}$ and $2926 \mathrm{~cm}^{-1}$, which were ascribed to the skeletal vibration of $\mathrm{C}-\mathrm{H}$ bonds. Besides, the coupling of the GPC 3 antibody was confirmed by the occurrence of a peak at $2852 \mathrm{~cm}^{-1}$ and $2922 \mathrm{~cm}^{-1}$ strengthening, representing the $\mathrm{C}-\mathrm{H}$ bonds vibration of the GPC3 antibody. The amount of GPC3 antibody modified on the C6/ MMSN-GPC3 was $9.98 \mu \mathrm{g} / \mathrm{mL}$. Zeta potential measurements (Figure 1E) indicated that the zeta potential of MMSN was $-24.33 \pm 0.42 \mathrm{mV}$. The surface charge of MMSN-NH $\mathrm{N}_{2}$ was converted to $17.77 \pm 1.23 \mathrm{mV}$ via modified by amino groups. After conjugation of $\mathrm{Mal}_{-} \mathrm{PEG}_{2000^{-}}$ $\mathrm{COOH}$ and GPC3 antibody, the surface charges were changed to $-3.73 \pm 0.07 \mathrm{mV}$ and $-26.43 \pm 0.25 \mathrm{mV}$, which showed that $\mathrm{C6} / \mathrm{MMSN}-\mathrm{GPC} 3$ had been successfully prepared. Meanwhile, C6/MMSN-GPC3 was stable, and C6 was rarely released in DMEM (Figure 1F). From the STEM images (Figure 1G), the corresponding elemental analysis clearly showed a core-shell structure and distinguished the nanoparticles from the inside to the outside: the iron oxide core and the silica shell. Furthermore, the fluorescent RhB-GPC3 antibody was reacted with $\mathrm{C} 6 /$ MMSN- $\mathrm{PEG}_{2000}$, and bright RhB and C6 fluorescence on particles indicated that the GPC 3 antibody could be effectively conjugated on the surface (Figure $1 \mathrm{H}$ ). Overall, these results indicated that $\mathrm{C6} / \mathrm{MMSN}-\mathrm{GPC} 3$ was constructed successfully. C6/MMSN-GPC3 was developed for high-specific isolation and instant observation of HCC CTC. C6/MMSN-GPC3 was designed by using $\mathrm{Fe}_{3} \mathrm{O}_{4}$ nanoparticle as a core for magnetic isolating, silica coating for GPC3 antibody conjugation and fluorescent molecular loading. The GPC3 receptor with high, stable and specific expression on HCC CTC was selected as the target to capture HCC CTC. Coumarin 6 (C6) with fluorescence properties made it convenient to observe the captured CTC by fluorescence in real-time.

\section{C6/MMSN-GPC3 Displayed High-Specific Capture Efficiency on HepG2 Cells}

To determine superior conditions for capturing targeted tumor cells, the optimal assay concentration and time of C6/MMSN-GPC3 were screened. GPC3-positive HCC cell line (HepG2) was selected as the experimental group, and 
A

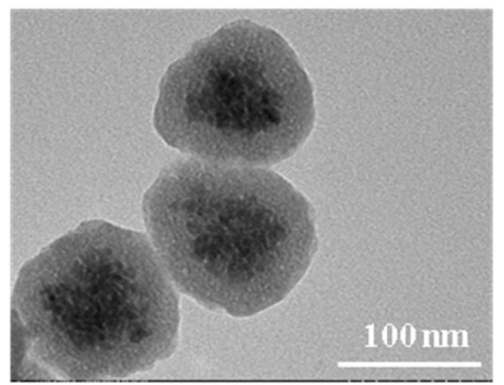

D

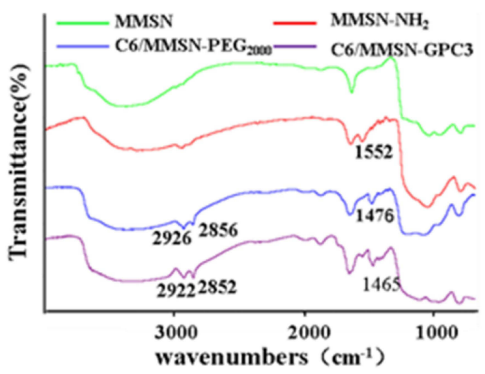

G
B

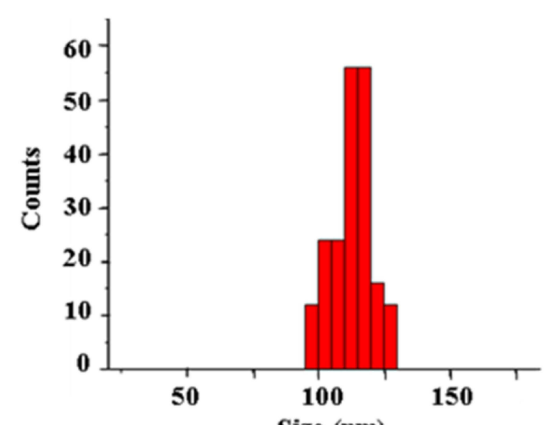

E

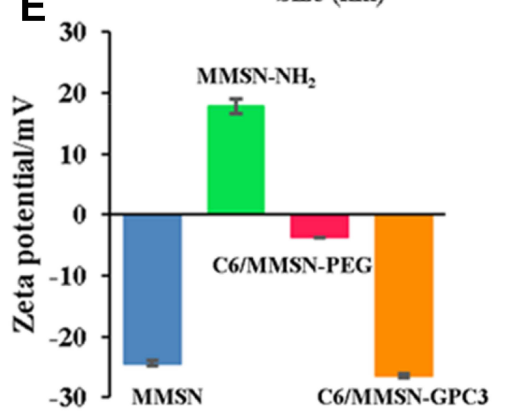

C
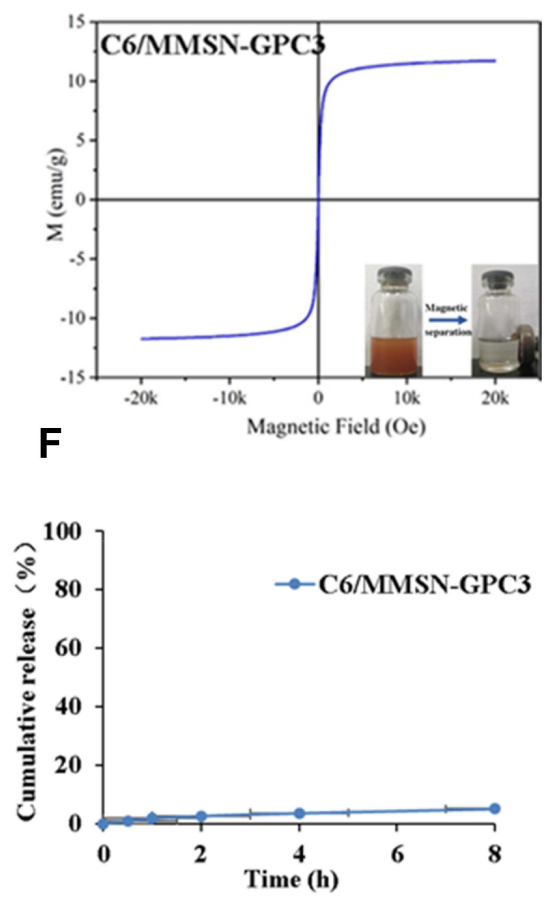

H

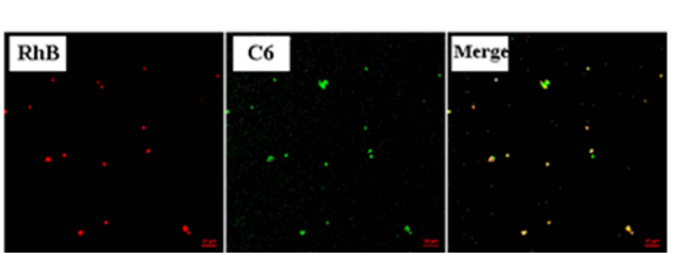

Figure I GPC3 antibody was successfully conjugated on the surface of C6/MMSN-GPC3. (A) TEM of C6/MMSN-GPC3. (B) The size of C6/MMSN-GPC3. (C) Hysteresis curves of C6/MMSN-GPC3. (D) FTIR of MMSN, MMSN-NH 2 , C6/MMSN-PEG 2000 , C6/MMSN-GPC3. (E) The potential of MMSN, MMSN-NH 2 , C6/MMSN-PEG 2000 , C6/ MMSN-GPC3. (F) The release of C6 from C6/MMSN-GPC3. (G) Elemental analysis of C6/MMSN- GPC3. (H) Representative confocal laser scanning microscopy (CLSM) images of RhB labeled C6/MMSN-GPC3.GPC3 antibody labeled with RhB conjugated on C6/MMSN-PEG 2000.

the GPC3-negative Jurkat $\mathrm{T}$ cell line was chosen as the control group. As the incubation time increased, the capture efficiency was also improved. As the incubation time increased to $30 \mathrm{~min}$, the capture efficiency was up to $96 \%$. The capture efficiency showed scarcely increased with the elongation of time (Figure 2A). The same result could be intuitively drawn from microscopy images (Figure 2B). The number of captured cells was growing with the incubation time increasing, and there were barely changes, while the time was reaching $30 \mathrm{~min}$. In Figure $2 \mathrm{C}$, with the increase of C6/MMSN-GPC3 concentration from 50 $\mu \mathrm{g} / \mathrm{mL}$ to $600 \mu \mathrm{g} / \mathrm{mL}$, the capture efficiency increased to $92 \%$. As the concentration reached $400 \mu \mathrm{g} / \mathrm{mL}$, the capture efficiency remained nearly unchanged with larger dosages $(500 \mu \mathrm{g} / \mathrm{mL}$ and $600 \mu \mathrm{g} / \mathrm{mL})$. The microscopy images showed the same result (Figure 2D). As a result, the optimal incubation time selected was $30 \mathrm{~min}$, and the dosage of C6/MMSN-GPC3 used in isolation was 400 $\mu \mathrm{g} / \mathrm{mL}$. Simultaneously, the capture efficiency of Jurkat T cells was almost unchanged with the incubation concentration and time altering, indicating that C6/MMSN-GPC3 displayed the high-specific combination with HepG2 cells and non-specific binding with Jurkat T cells.

\section{C6/MMSN-GPC3 Exhibited Specific Recognition Ability on HepG2 Cells}

The targeting binding ability of C6/MMSN-GPC3 was studied on HepG2 cells by fluorescence microscopy, and the mean fluorescence intensity (MFI) was analyzed by flow cytometry. For the adherent and suspensory HepG2 cells, obvious green color could be seen in the C6/MMSNGPC3 group compared with the C6/MMSN-PEG 2000 group (Figure 3A and D). According to flow cytometric 
A

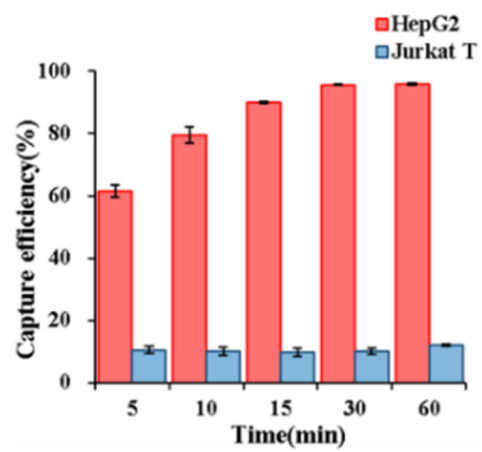

B

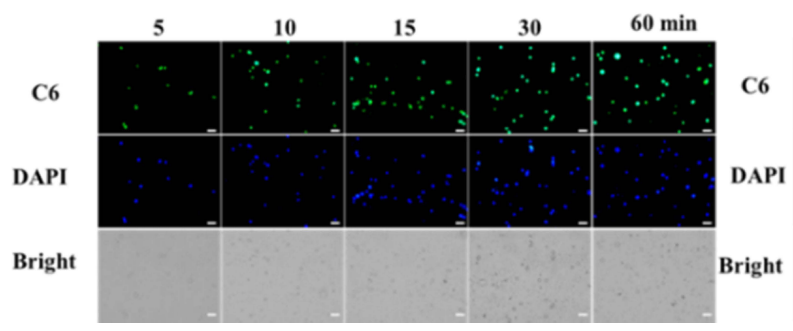

C

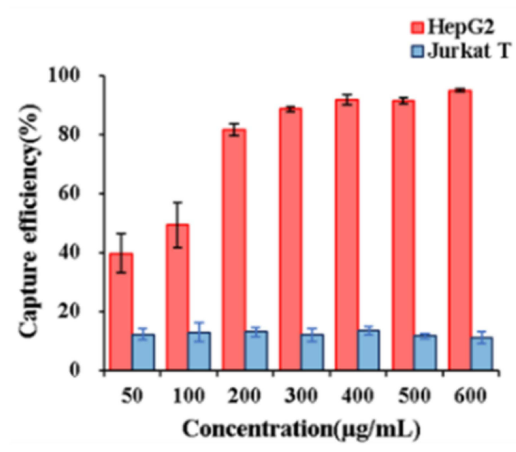

D

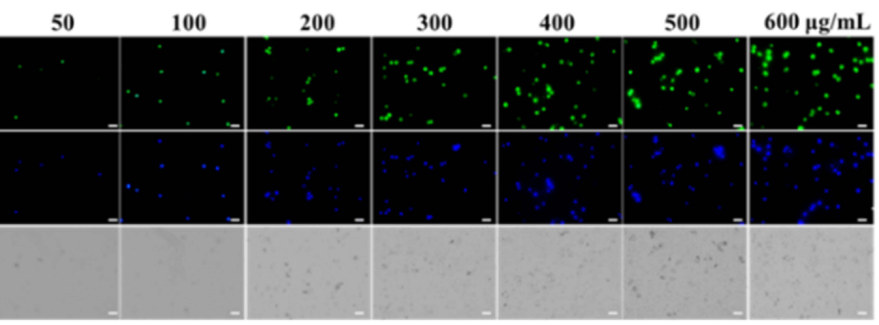

Figure 2 C6/MMSN-GPC3 displayed high-specific capture efficiency on HepG2 cells. The optimization procedure was evaluated by capture efficiency and microscopy images. (A) Capture efficiency and (B) microscopy images with different incubation time. (C) Capture efficiency and (D) microscopy images in different concentrations. Data were given as mean \pm SD $(n=3)$.

A

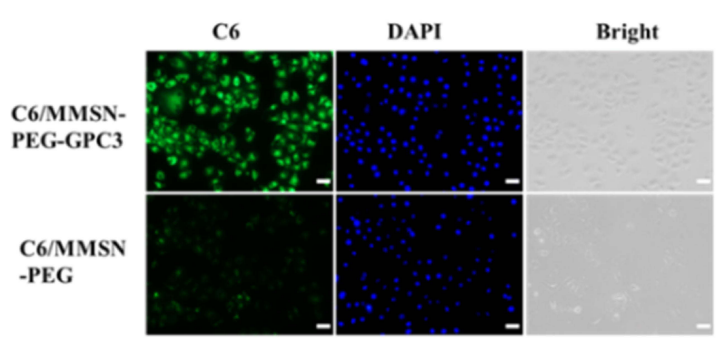

D

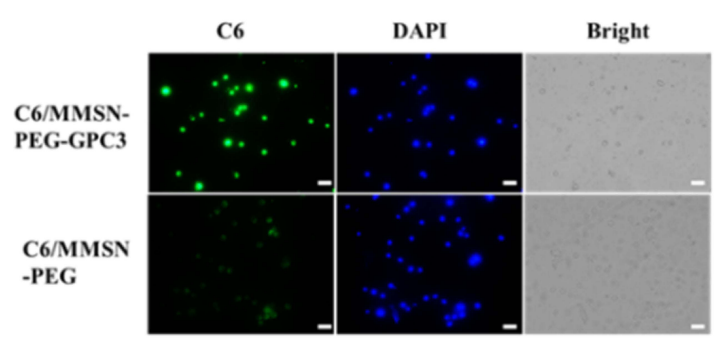

B

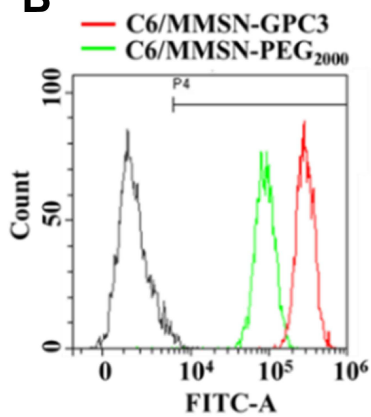

E

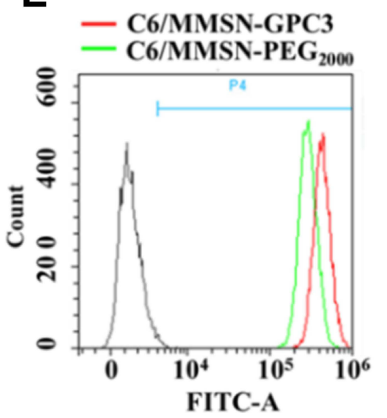

C

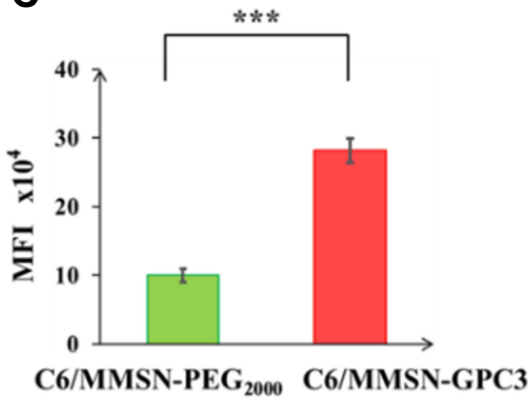

$\mathbf{F}$

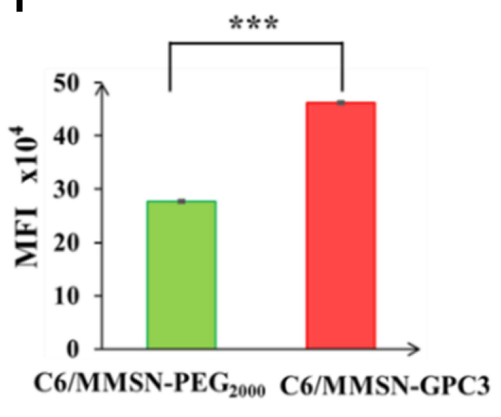

Figure 3 The GPC3-targeting nanodevice exhibited specific recognition ability on HepG2 cells conducive to further application in clinic. Inverted fluorescence microscope images and flow cytometry (FCM) analysis: (A-C): for the adherent HepG2 cells; (D-F): for the suspensory HepG2 cells. Data were given as mean \pm SD $(n=3)$, *** $p<0.001$.

analysis (Figure 3B, C, E and F), a significant difference in MFI between C6/MMSN-GPC3 and C6/MMSN-PEG 2000 was observed $(p<0.001)$. The same result could be obtained on other cancer cell lines (Hepa1-6 and Huh7 cells), which also overexpressed GPC3 (Figure S1). These results above exhibited that C6/MMSN-GPC3 displayed the specific targeting binding ability in the cells with high GPC3 expression. 


\section{C6/MMSN-GPC3 Showed Superior Capture Performance Compared with Conventional EpCAM Magnetic Beads in Mimicking Clinical Samples}

To demonstrate the superior capture performance of the C6/MMSN-GPC3, we comparatively investigated the enrichment performance between C6/MMSN-GPC3 and available commercial MACS $^{\circledR}$ Beads in mimic clinical samples. The cell recovery (\%) of C6/MMSN-GPC3 increased in $10^{6}$ HL-60 cells (from $49.7 \%$ to $83.0 \%$ ) and in whole blood (from $42 \%$ to $80.3 \%$ ) compared with MACS ${ }^{\circledR}$ Beads (Figure 4A). And the cells image captured with C6/MMSN-GPC3 and MACS ${ }^{\circledR}$ Beads were shown in Figure 4B. The result showed that the capture ability of C6/MMSN-GPC3 was superior to MACS ${ }^{\circledR}$ Beads in mimic clinical samples. Furthermore, it demonstrated the potential application in the following clinical samples. To further obtain the detection limit of the C6/MMSN-GPC3, different amounts of HepG2 cells with Hoechst 33342 stained $(10,20,50,100,150$, and 200 , respectively) were spiked into $10^{6}$ HL-60 cells. The results demonstrated that the $\mathrm{C} 6 / \mathrm{MMSN}-\mathrm{GPC} 3$ was able to capture CTC efficiently with detection limits as low as 10 (Figure 4C). The results above indicated C6/ MMSN-GPC3 was more specific and efficient than MACS $^{\circledR}$ Beads in capturing HCC CTC. What is more, the low detection limit of the new capturing system established a sound basis for isolating rare CTC from HCC patients' blood. Since the concentration of CTC in the blood was extremely low (one to hundreds of CTCs in a billion blood cells), ${ }^{22,29}$ it was difficult to realize
CTC purification from patients to mimic clinical samples for evaluation. Using human cancer cell lines in vitro to mimic clinical CTC samples as a widely accepted method has been applied to many researches. ${ }^{30-34}$ We also learned from the methods. HepG2 as human hepatocellular carcinoma cell lines was equally highly expressed in GPC3 on the surface with HCC CTC. Therefore, HepG2 was selected as the HCC CTC model in the study.

\section{C6/MMSN-GPC3 Showed Negligible Influence on Cell Viability Migration and Proliferation Ability of Captured Cells}

The structural and functional integrities of captured CTC by C6/MMSN-GPC3 were essential for the subsequent analysis so that the migration, the cytotoxicity in vitro, and proliferation experiments were conducted. The wound healing assay showed that the wound closure rate was growing in the process of culturing $24 \mathrm{~h}$ in FBS-free medium. Furthermore, there were no obvious changes between the controlled group and captured group, demonstrating that they had a similar migration ability (Figure 5A and B). The C6/MMSN-GPC3 showed over $80 \%$ cell viability even at a concentration of $400 \mu \mathrm{g} / \mathrm{mL}$ and displayed good biocompatibility and safety (Figure 5C). Moreover, the captured HepG2 cells could continue to proliferate without noticeable shapestructural changes even after culturing for three passages (Figure 5D). The results showed that the separation process had little impact on the cells. Therefore, C6/ MMSN-GPC3 may be applied as an effective tool for CTC downstream analysis.
A

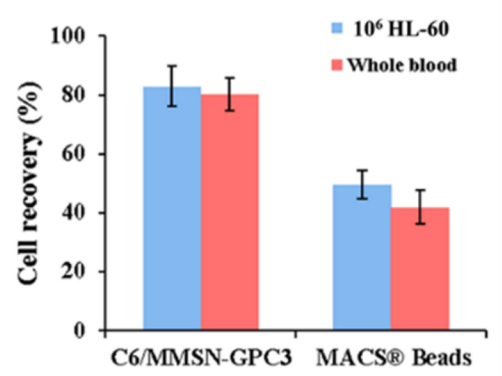

B

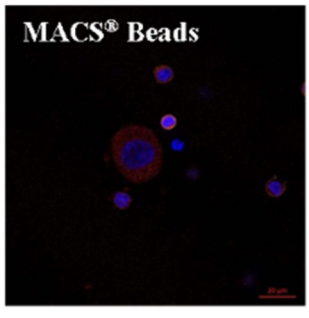

C

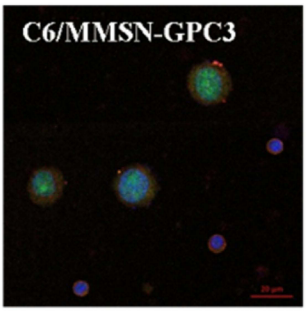

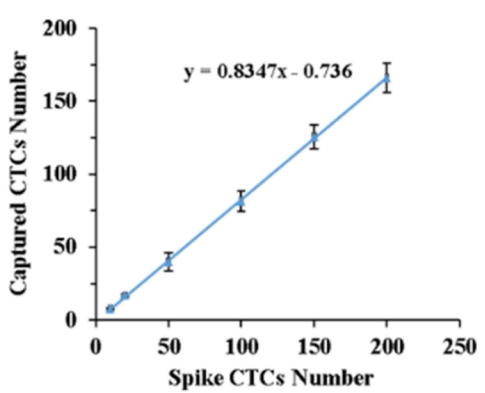

Figure 4 C6/MMSN-GPC3 showed superior capture performance compared with conventional EpCAM magnetic beads (MACS ${ }^{\circledR}$ Beads) in mimicking clinical samples. (A) The cell recovery (\%) of C6/MMSN-GPC3 and MACS ${ }^{\circledR}$ Beads in $10^{6} \mathrm{HL}-60$ cells and whole blood, Data were given as mean \pm SD $(n=3)$, $(\mathbf{B})$ the cells image captured with C6/MMSN-GPC3 and MACS ${ }^{\circledR}$ Beads. (C) Detection limits of the C6/MMSN-GPC3 in the mimic clinical samples with rare cells (I0-200 cells $\mathrm{mL}^{-1}$ ). Data were given as mean $\pm \mathrm{SD}(\mathrm{n}=3)$. 
A

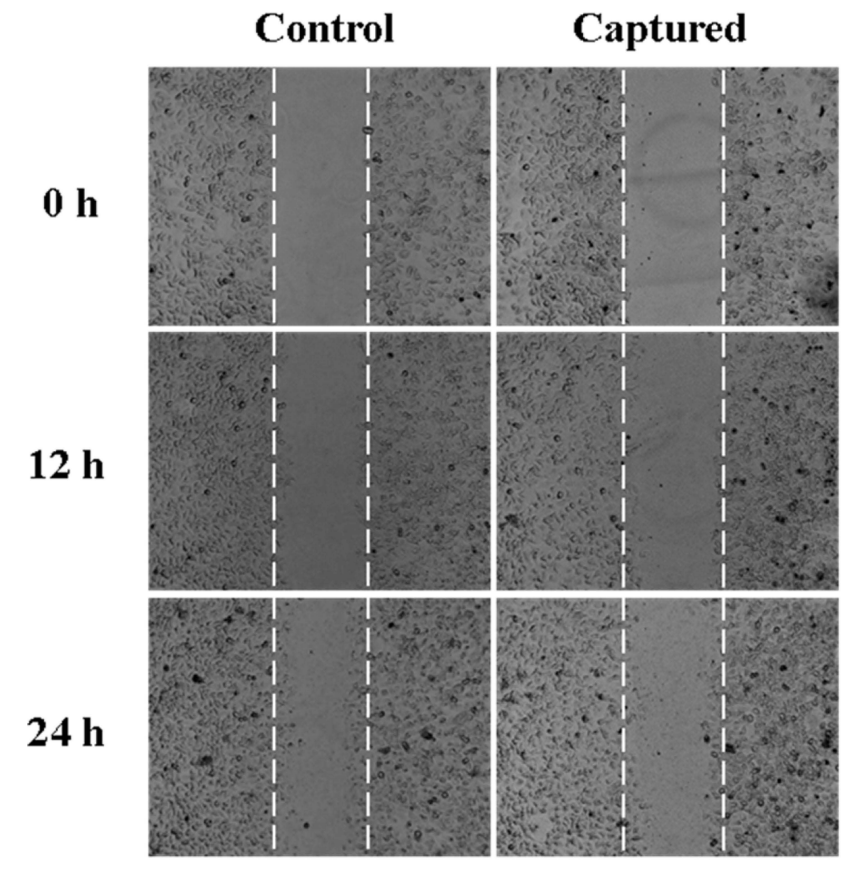

B

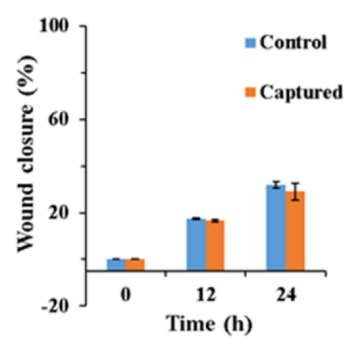

D

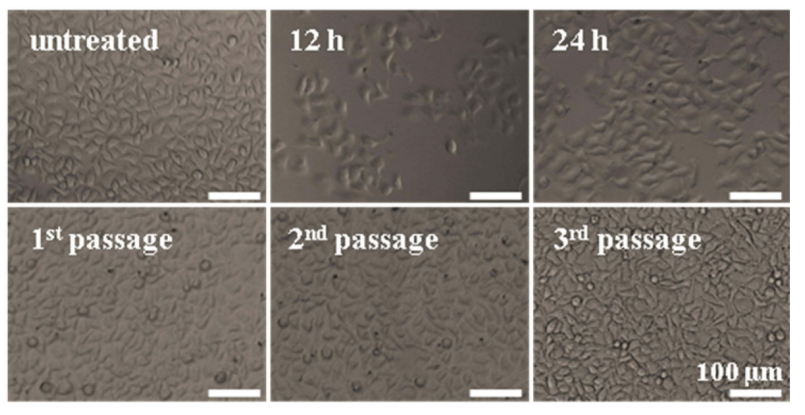

Figure 5 The captured process of C6/MMSN-GPC3 showed a negligible influence on cell viability migration and proliferation ability of captured cells. (A) Wound healing assays $(0 \mathrm{~h} 12 \mathrm{~h}$, and $24 \mathrm{~h})$ of captured HepG2 cells and untreated HepG2 cells and $(\mathbf{B})$ the wound closure rate $(\%)$ counted at different times $(\mathrm{n}=3)$. (C) In vitro cytotoxicity of various concentrations of C6/MMSN-GPC3. (D) Light field images of the captured HepG2 cells culturing for $3^{\text {rd }}$ passage.

\section{C6/MMSN-GPC3 Exhibited High-Specific Isolation and Instant Observation of CTC from HCC Patients' Blood Samples}

Moreover, C6/MMSN-GPC3 was put into practice with blood samples from $20 \mathrm{HCC}$ patients and three normal humans (The blood donors' information was provided in Supplementary Tables 1-3). The captured CTC were recognized using a traditional three-color immunofluorescence method. Observed under CLSM, the combined image (Figure 6A) was used to distinguish CTC (CD45 $-/ \mathrm{CK} 18+/ \mathrm{DAPI}+, 10 \mu \mathrm{m}<$ cell size $<30 \mu \mathrm{m})$ from $\mathrm{WBC}$ (CD45+/CK18-/DAPI + , cell size $<15 \mu \mathrm{m}) .7$ cases of HCC patients' samples were detected by C6/MMSNGPC3. The number of CTC for each patient was summarized in Figure 6B, and 2-42 CTC were detected in $2 \mathrm{~mL}$ HCC patients' blood, yet there were no CTC discovered in healthy volunteer's blood. Typical CLSM images of the captured CTC from the seven cases of clinical patients were displayed in Figure 6C. The experiment demonstrated that C6/MMSN-GPC3 could capture CTC from HCC patients' peripheral blood effectively. At the same time, the capture performance between C6/MMSNGPC3 and MACS ${ }^{\circledR}$ Beads was evaluated in 13 cases of patients (Figure 6D and Supplementary Table 4). The result showed that the capture ability of C6/MMSNGPC3 was superior to MACS ${ }^{\circledR}$ Beads in clinical samples and the capture efficiency was improved by $83.3-350 \%$. The case (Number as 11) was with small hepatocellular carcinoma (Stage I). In this case, 2 CTCs were detected by C6/MMSN-GPC3 and no CTC was detected by MACS ${ }^{\circledR}$ Beads. The result indicated that CTC could be separated in the early stage of HCC by C6/MMSN-GPC3, which was beneficial for HCC early diagnosis. In one case of postsurgery HCC patient (Supplementary Table 4), 5 CTCs were detected by C6/MMSN-GPC3 and no CTC was detected by $\mathrm{MACS}^{\circledR}$ beads, indicating the potential ability of prognosis evaluation of C6/MMSN-GPC3.

\section{Conclusion}

In summary, a novel CTC capturing platform based on magnetic mesoporous silica nanoparticles modified with the GPC3 antibody (C6/MMSN-GPC3) was developed for HCC CTC enrichment. The capture efficacy of C6/ MMSN-GPC3 was higher than that of traditional EpCAM immunomagnetic beads (MACS ${ }^{\circledR}$ Beads) in synthetic clinical sample and clinical samples. The captured CTCs maintained high viability, good migration ability 
A

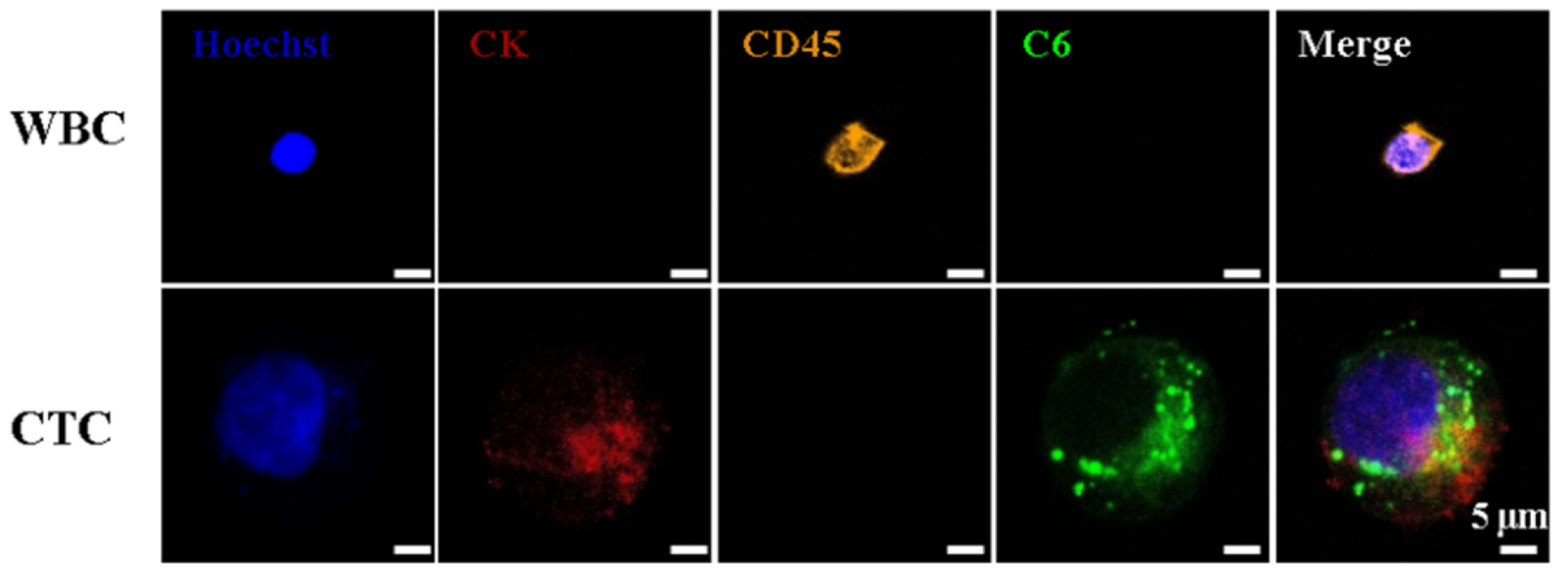

B

D

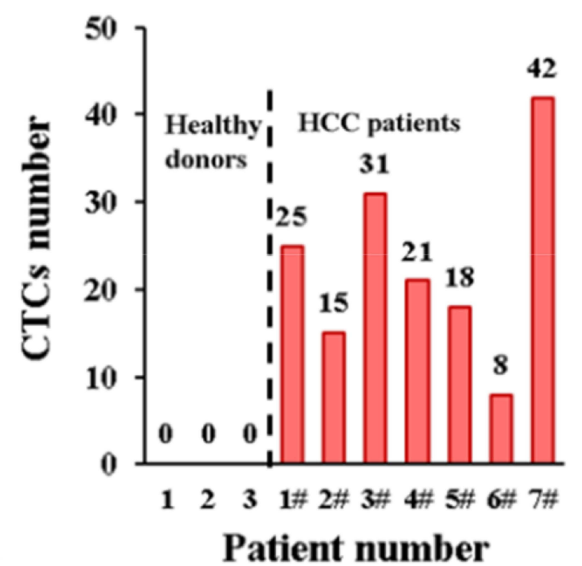

C

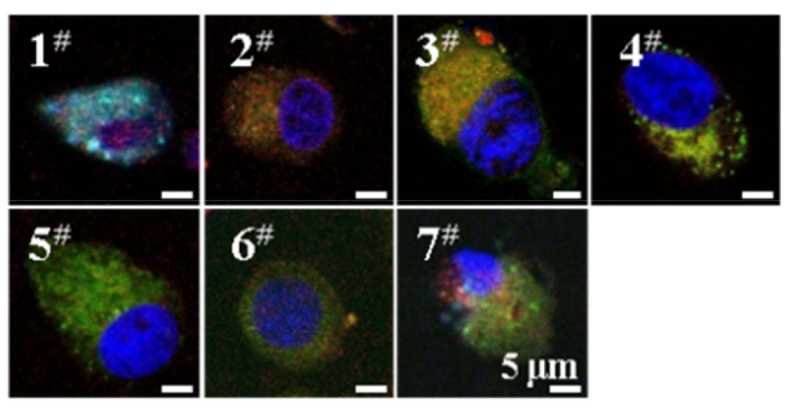

口C6/MMSN-GPC3

$\square$ MACS\& Beads

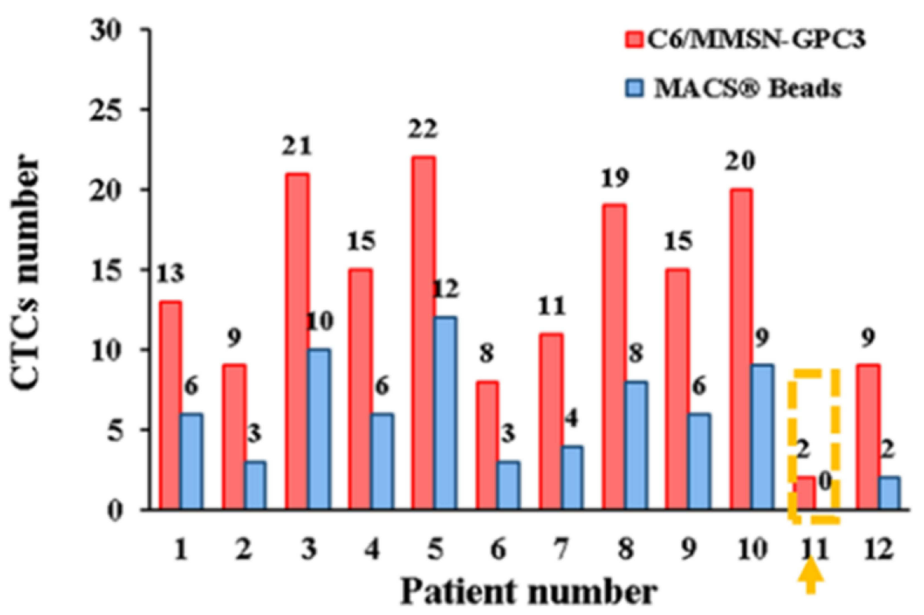

Figure 6 C6/MMSN-GPC3 exhibited high-specific isolation and instant observation of CTC from HCC patients' blood samples. (A) CLSM images of captured CTC and WBC identified with the three-color ICC. (B) CTC enumeration captured by C6/MMSN-GPC3 from 7 cases of HCC patients' samples (C) Typical CTC images of the 7 cases of HCC patients' samples. Scale bar: $5 \mu \mathrm{m}$. (D) CTCs number captured by C6/MMSN-GPC3 and MACS ${ }^{\circledR}$ Beads in 12 cases of clinical HCC patients' blood samples. The case marked with arrow and dotted box was with small hepatocellular carcinoma (Stage I).

and successfully recultured in vitro for several passages so as to facilitate subsequent analysis. The C6/MMSN-GPC3 achieved the selective capture and accurate detection of CTC from HCC patients' blood samples, and successfully separated CTC from one patient with early stage of HCC (Stage I) and one post-surgery patient, further indicating the potential ability of C6/MMSN-GPC3 for HCC early diagnosis and prognosis evaluation. It was hoped that the 
new CTC capture nanoplatform provided a new strategy for HCC CTC enrichment.

\section{Acknowledgments}

All experiments including blood samples were performed in compliance with the Declaration of Helsinki. This work was supported by the National Natural Science Foundation of China (81773652) and the Young Scholar Program of Shandong University (YSPSDU, 2017WLJH40). The authors appreciated genuine assistance from Qilu Hospital of Shandong University and Shandong Provincial Hospital. Special thanks was given to the volunteers for donating blood. The authors were grateful to the Pharmaceutical biology sharing platform of Shandong University for supporting the cellular experiments. The authors were thankful to Translational Medicine Core Facility of Shandong University for the use of the instrument. The authors thanked the Microscopy Characterization Facility of Shandong University for the availability of CLSM.

\section{Disclosure}

The authors declare no conflict of interest.

\section{References}

1. Siegel RL, Miller KD, Jemal A. Cancer statistics, 2020. Ca Cancer J Clin. 2020;70(1):7-30. doi:10.3322/caac.21590

2. Llovet JM, Villanueva A, Lachenmayer A, Finn RS. Advances in targeted therapies for hepatocellular carcinoma in the genomic era (vol 12, pg 408, 2015). Nat Rev Clin Oncol. 2015;12(7). doi:10.1038/ nrclinonc. 2015.121

3. Jeffrey GP, Gordon LG, Hill MM, Ramm GA. Liquid biopsies for hepatocellular cancer and their potential in clinical practice. Hepatology. 2020;71(6):2160-2162. doi:10.1002/hep.31168

4. Alix-Panabieres C. Perspective: the future of liquid biopsy. Nature. 2020;579(7800):S9-S9. doi:10.1038/d41586-020-00844-5

5. Pantel K, Alix-Panabieres C. Liquid biopsy and minimal residual disease - latest advances and implications for cure. Nat Rev Clin Oncol. 2019;16(7):409-424. doi:10.1038/s41571-019-0187-3

6. De Rubis G, Krishnan SR, Bebawy M. Liquid biopsies in cancer diagnosis, monitoring, and prognosis. Trends Pharmacol Sci. 2019;40 (3):172-186. doi:10.1016/j.tips.2019.01.006

7. Ahn JC, Teng PC, Chen PJ, et al. Detection of circulating tumor cells and their implications as a novel biomarker for diagnosis, prognostication, and therapeutic monitoring in hepatocellular carcinoma. Hepatology. 2020. doi:10.1002/hep.31165

8. Zhong XM, Zhang HT, Zhu Y, et al. Circulating tumor cells in cancer patients: developments and clinical applications for immunotherapy. Mol Cancer. 2020;19(1). doi:10.1186/s12943-020-1141-9

9. Massague J, Obenauf AC. Metastatic colonization by circulating tumor cells. Nature. 2016;529(7586):298-306. doi:10.1038/nature 17038

10. Joosse SA, Gorges TM, Pantel K. Biology, detection, and clinical implications of circulating tumor cells. Embo Mol Med. 2015;7 (1):1-11. doi:10.15252/emmm.201303698
11. Xue T, Wang SQ, Ou GY, et al. Detection of circulating tumor cells based on improved SERS-active magnetic nanoparticles. Anal Methods. 2019;11(22):2918-2928. doi:10.1039/C9AY00646J

12. Alix-Panabieres C, Pantel K. Challenges in circulating tumor cell research. Nat Rev Cancer. 2014;14(9):623-631. doi:10.1038/nrc3820

13. von Felden J, Garcia-Lezana T, Schulze K, Losic B, Villanueva A. Liquid biopsy in the clinical management of hepatocellular carcinoma. Gut. 2020;69(11):2025-2034. doi:10.1136/gutjnl-2019-320282

14. Riethdorf S, O'Flaherty L, Hille C, Pantel K. Clinical applications of the cell search platform in cancer patients. Adv Drug Deliver Rev. 2018;125:102-121. doi:10.1016/j.addr.2018.01.011

15. Zhang Y, Zhang XF, Zhang JL, et al. Microfluidic chip for isolation of viable circulating tumor cells of hepatocellular carcinoma for their culture and drug sensitivity assay. Cancer Biol Ther. 2016;17 (11):1177-1187. doi:10.1080/15384047.2016.1235665

16. Xie JJ, Lu YS, Dong HY, et al. Enhanced specificity in capturing and restraining circulating tumor cells with dual antibody-dendrimer conjugates. Adv Funct Mater. 2015;25(8):1304-1313. doi:10.1002/ adfm. 201403556

17. Zhou FB, Shang WT, Yu XL, Tian J. Glypican-3: a promising biomarker for hepatocellular carcinoma diagnosis and treatment. Med Res Rev. 2018;38(2):741-767. doi:10.1002/med.21455

18. Fu Y, Urban DJ, Nani RR, et al. Glypican-3-specific antibody drug conjugates targeting hepatocellular carcinoma. Hepatology. 2019;70 (2):563-576. doi: $10.1002 /$ hep.30326

19. Mu WW, Jiang DD, Mu SJ, Liang S, Liu YJ, Zhang N. Promoting early diagnosis and precise therapy of hepatocellular carcinoma by glypican-3-targeted synergistic chemo-photothermal theranostics. Acs Appl Mater Interfaces. 2019;11(26):23591-23604. doi:10.1021/ acsami.9b05526

20. Banko P, Lee SY, Nagygyorgy V, et al. Technologies for circulating tumor cell separation from whole blood. J Hematol Oncol. 2019;12:10. doi:10.1186/s13045-019-0735-4

21. Gribko A, Künzel J, Wünsch D, et al. Is small smarter? Nanomaterial-based detection and elimination of circulating tumor cells: current knowledge and perspectives. Int $J$ Nanomedicine. 2019;14:4187-4209. doi:10.2147/IJN.S198319

22. Shen ZY, Wu AG, Chen XY. Current detection technologies for circulating tumor cells. Chem Soc Rev. 2017;46(8):2038-2056. doi:10.1039/c6cs00803h

23. Chen JD, Chen L, Du SB, et al. High sensitive detection of circulating tumor cell by multimarker lipid magnetic nanoparticles and clinical verifications. J Nanobiotechnol. 2019;17(1). doi:10.1186/ s12951-019-0548-1

24. Khandare J, Qayyumi B, Prabhash K, et al. A highly efficient, low-cost, novel multicomponent nanosystem for rapid enumeration of circulating tumor cells. J Clin Oncol. 2019;37(15):e14516e14516. doi:10.1200/JCO.2019.37.15_suppl.e14516

25. PramaniK A, Jones S, Gao Y, et al. Multifunctional hybrid graphene oxide for circulating tumor cell isolation and analysis. Adv Drug Deliver Rev. 2018;125:21-35. doi:10.1016/j.addr.2018.01.004

26. Li Q, Liao Z, Han L, Li L, Song Y, Song E. Isolation and analysis of tumor cell subpopulations using biomimetic immuno-fluorescent magnetic multifunctional nanoprobes. Adv Funct Mater. 2020;30 (49). doi:10.1002/adfm.202004963

27. Mu SJ, Liu YJ, Wang TQ, et al. Unsaturated nitrogen-rich polymer poly(L-histidine) gated reversibly switchable mesoporous silica nanoparticles using "graft to" strategy for drug controlled release. Acta Biomater. 2017;63:150-162. doi:10.1016/j.actbio.2017.08.050

28. Wu S, Gu L, Qin J, et al. Rapid label-free isolation of circulating tumor cells from patients' peripheral blood using electrically charged Fe3O4 nanoparticles. ACS Appl Mater Interfaces. 2020;12 (4):4193-4203. doi:10.1021/acsami.9b16385

29. Jackson JM, Witek MA, Kamande JW, et al. Materials and microfluidics: enabling the efficient isolation and analysis of circulating tumor cells. Chem Soc Rev. 2017;46(14):4245-4280. doi:10.1039/c7cs00016b 
30. Zhou X, Luo B, Kang K, et al. Leukocyte-repelling biomimetic immunomagnetic nanoplatform for high-performance circulating tumor cells isolation. Small. 2019;15(17):e1900558. doi:10.1002/ smll.201900558

31. Ding C, Zhang C, Cheng S, et al. Multivalent aptamer functionalized Ag2S nanodots/hybrid cell membrane-coated magnetic nanobioprobe for the ultrasensitive isolation and detection of circulating tumor cells. Adv Funct Mater. 2020;30(16):1909781. doi:10.1002/adfm.20 1909781
32. Nagrath S, Sequist LV, Maheswaran S, et al. Isolation of rare circulating tumor cells in cancer patients by microchip technology. Nature. 2007;450(7173):1235-1239. doi:10.1038/nature06385

33. Yoon HJ, Kim TH, Zhang Z, et al. Sensitive capture of circulating tumor cells by functionalized graphene oxide nanosheets. Nat Nanotechnol. 2013;8(10):735-741. doi:10.1038/nnano.2013.194

34. Warkiani ME, Khoo BL, Wu L, et al. Ultra-fast, label-free isolation of circulating tumor cells from blood using spiral microfluidics. Nat Protoc. 2016;11(1):134-148. doi:10.1038/nprot.2016.003
International Journal of Nanomedicine

\section{Publish your work in this journal}

The International Journal of Nanomedicine is an international, peerreviewed journal focusing on the application of nanotechnology in diagnostics, therapeutics, and drug delivery systems throughout the biomedical field. This journal is indexed on PubMed Central, MedLine, CAS, SciSearch ${ }^{\circledR}$, Current Contents ${ }^{\circledR} /$ Clinical Medicine, $^{2}$
Dovepress

Journal Citation Reports/Science Edition, EMBase, Scopus and the Elsevier Bibliographic databases. The manuscript management system is completely online and includes a very quick and fair peer-review system, which is all easy to use. Visit http://www.dovepress.com/ testimonials.php to read real quotes from published authors. 